\title{
Response of Phytochemicals in Bush Tea (Athrixia phylicoides DC.) as Influenced by Selected Micronutrients
}

\author{
Maedza K. Vuwani and Mpumelelo Nkomo \\ Department of Agriculture and Animal Health, University of South Africa, \\ Private Bag X6, Florida, 1710, South Africa
}

\author{
Wonder Ngezimana \\ Marondera College of Agricultural Sciences and Technology, University of \\ Zimbabwe, P.O. Box 35, Marondera, Zimbabwe
}

Nokwanda P. Makunga

Department of Botany and Zoology, Stellenbosch University, Private Bag X1, Matieland, Stellenbosch, 7602, South Africa

\author{
Fhatuwani N. Mudau' \\ Department of Agriculture and Animal Health, University of South Africa, \\ Private Bag X6, Florida, 1710, South Africa
}

Additional index words. GC-MS, herbal tea, LC-MS

\begin{abstract}
Bush tea (Athrixia phylicoides DC.) is an herbal beverage and medicinal plant indigenous to South Africa. This study evaluated the effects of micronutrients on bush tea quality. Treatments consisted of single applications of zinc $(\mathrm{Zn})$, copper $(\mathrm{Cu})$, boron $(\mathrm{Bo})$, iron $(\mathrm{Fe})$, and magnesium $(\mathrm{Mg})$ at three levels $(50,100$, and $150 \mathrm{~mL} / \mathrm{L})$ and a combination of all micronutrients. A control treatment with no spray was also included. Tea samples were analyzed using head space solid phase microextraction gas chromatography linked to mass spectrometry (HS-SPME-GC-MS). A significant change in the metabolite profile of bush tea was noted. Five major compounds were identified $(>80 \%$ identification probability) namely alpha-pinene, beta-pinene, myrcene, beta-caryophyllene, and caryophyllene oxide. A linear relationship between percentage leaf tissues and treatment levels of micronutrients in bush tea was also observed. The liquid chromatography linked to mass spectrometry (LC-MS) showed no significant qualitative difference between the control and the micronutrient treatments. There were significant quantitative differences between the control and treatments applied at 50 and $100 \mathrm{~mL} / \mathrm{L}$ and the combination $(\mathrm{B}+\mathrm{Zn}+\mathrm{Fe}+\mathrm{Cu}+\mathrm{Mg}$ ) applied at 10 and $20 \mathrm{~mL} / \mathrm{L}$. The application of micronutrients did have an influence on the metabolite quantities as has been reported with most secondary metabolite fluctuations caused by plant-environment interactions. Altering the micronutrient application may be a possible solution in achieving commercial agricultural production of this medicinal beverage.
\end{abstract}

Athrixia phylicoides DC of the Asteraceae family (commonly known as bush tea) presents South Africa with a substantial opportunity to explore new industries with various products. Apart from being used as a tea, the bush tea plant has potential in the cosmetic industry, as well as food and beverage industry as an additive to various products such as ready-to-drink beverages, fruit juice mixtures and is used as medicine for various

Received for publication 23 Sept. 2016. Accepted for publication 29 Nov. 2016

The authors are grateful to the National Research Foundation (NRF) and the Gauteng Department of Agriculture and Rural Development (GDARD) for funding. The authors wish to declare that we do not have any conflict of interests with respect to financial, personal, and organizational relationships which may influence the work negatively.

${ }^{1}$ Corresponding author. E-mail: mudaufn@unisa. ac.za. beverage and medicinal industry but reduce harvesting pressure. Current research has shown that yields and quality can be improved with fertilization (Mudau et al., 2005, 2007), pruning, and application of growth regulators (Maudu et al., 2013). Among these agronomic practices, application of $\mathrm{N}, \mathrm{P}$, and $\mathrm{K}$ fertilizers was reported to have a pronounced effect on leaf total polyphenol content in Camellia sinensis (Owuor et al., 1991, 2000) and in bush tea (Mudau et al., 2005, 2007).

Application of N, P, and $\mathrm{K}$ was also found to improve the accumulation of carbohydrates for plant growth (Wanyoko, 1983) and to increase photosynthetic rates (Haukioja et al., 1998). This resulted in the biosynthesis of carbon-based secondary metabolites, such as flavonoids, phenolic acids, and tannins, known as total polyphenols, which are antioxidant in nature (Haukioja et al., 1998). Nutrient-deficient plants often have lower growth rates and higher concentrations of carbon-based (nonnitrogen-containing) secondary compounds (CBSCs) than do plants with access to ample nutrients (Bryant et al., 1983; Coley et al., 1985). This negative correlation between concentrations of CBSCs and plant growth rate, or levels of nutrients in plant tissues, is assumed to indicate a trade-off between plant growth and the production of defensive compounds (Bryant et al., 1987).

Trace elements such as zinc, aluminum, copper, and boron are key components in many biological compounds and play a significant role in increasing photosynthesis (Ibrahim et al., 2011), photosynthetic active radiation $(P A R)$ absorption, as well as the production of secondary metabolites (Ibrahim and Hawa, 2013). However, much focus has been on $\mathrm{N}, \mathrm{P}$, and $\mathrm{K}$ as the main nutrients affecting growth and development with little attention to trace elements.

Micronutrients such as manganese, zinc, copper, iron, magnesium, and boron are beneficial to tea (Camellia sinensis) at specific levels (Omwoyo et al., 2014; Sedaghathoor et al., 2009). The practice of application of micronutrients to tea to improve growth, productivity (Mudau, 2007), and the effects on metabolite profiles of $C$. sinensis has been carried out (Sedaghathoor et al., 2009; Street et al., 2006). However, following a previous study by Maedza et al. (2016) on the effect of micronutrient foliar application on bush tea, the objective of this study was to evaluate the response of phytochemicals as influenced by selected micronutrients on $A$. phylicoides.

\section{Materials and Methods}

Experimental site. The study was conducted at the University of South Africa (Florida Science Campus) lat. S26 ${ }^{\circ} .501$ and long. E27 54.113 , during the 2013/ 2014 summer and winter seasons. The site has a humid subtropical climate (hot, usually humid summers, and mild to cool winters). Site experiences minimum temperatures of 13.1 to $15.0^{\circ} \mathrm{C}$, maximum temperatures of 29.1 to $32.1^{\circ} \mathrm{C}$ with an average rainfall of 23 


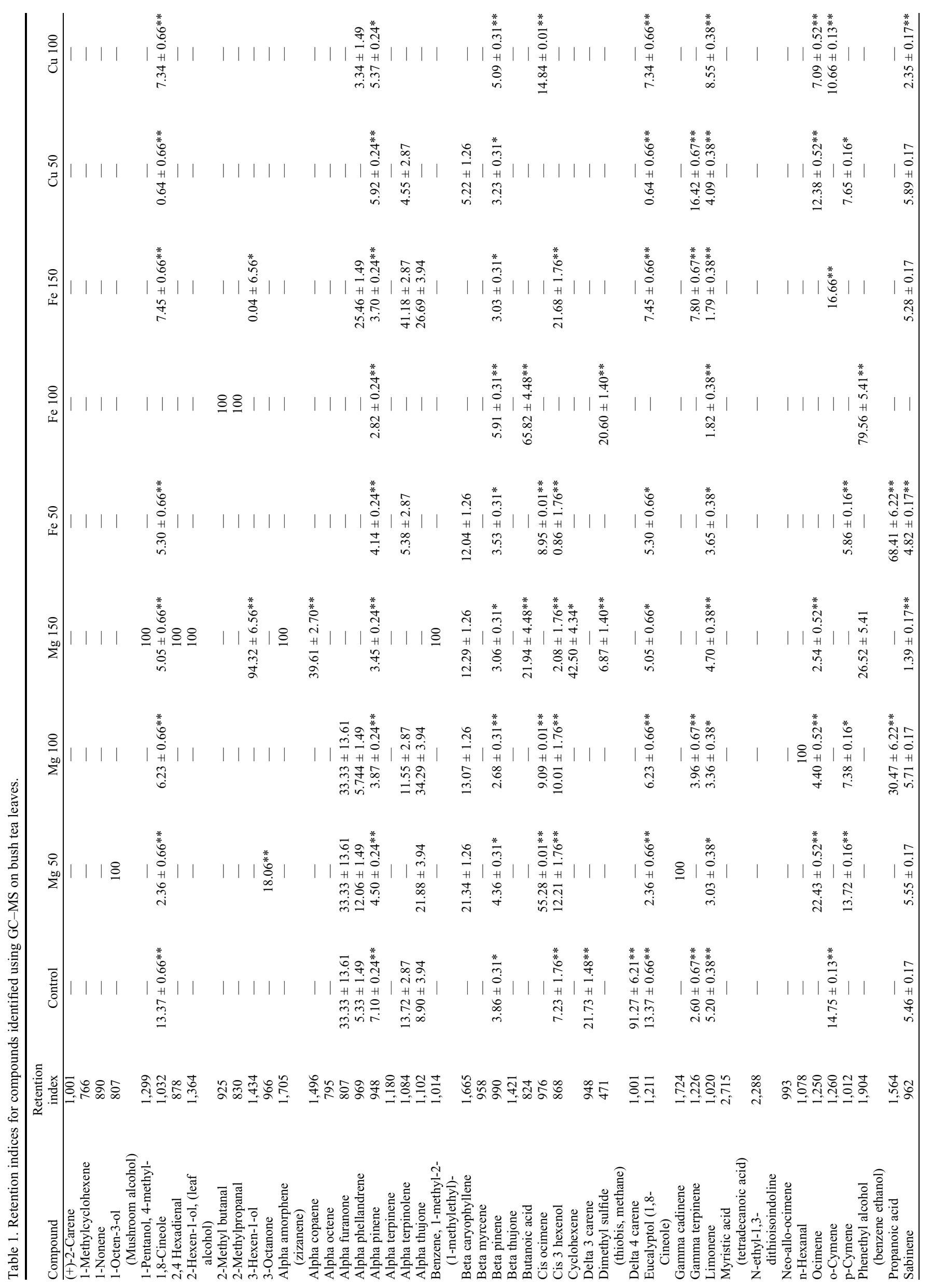




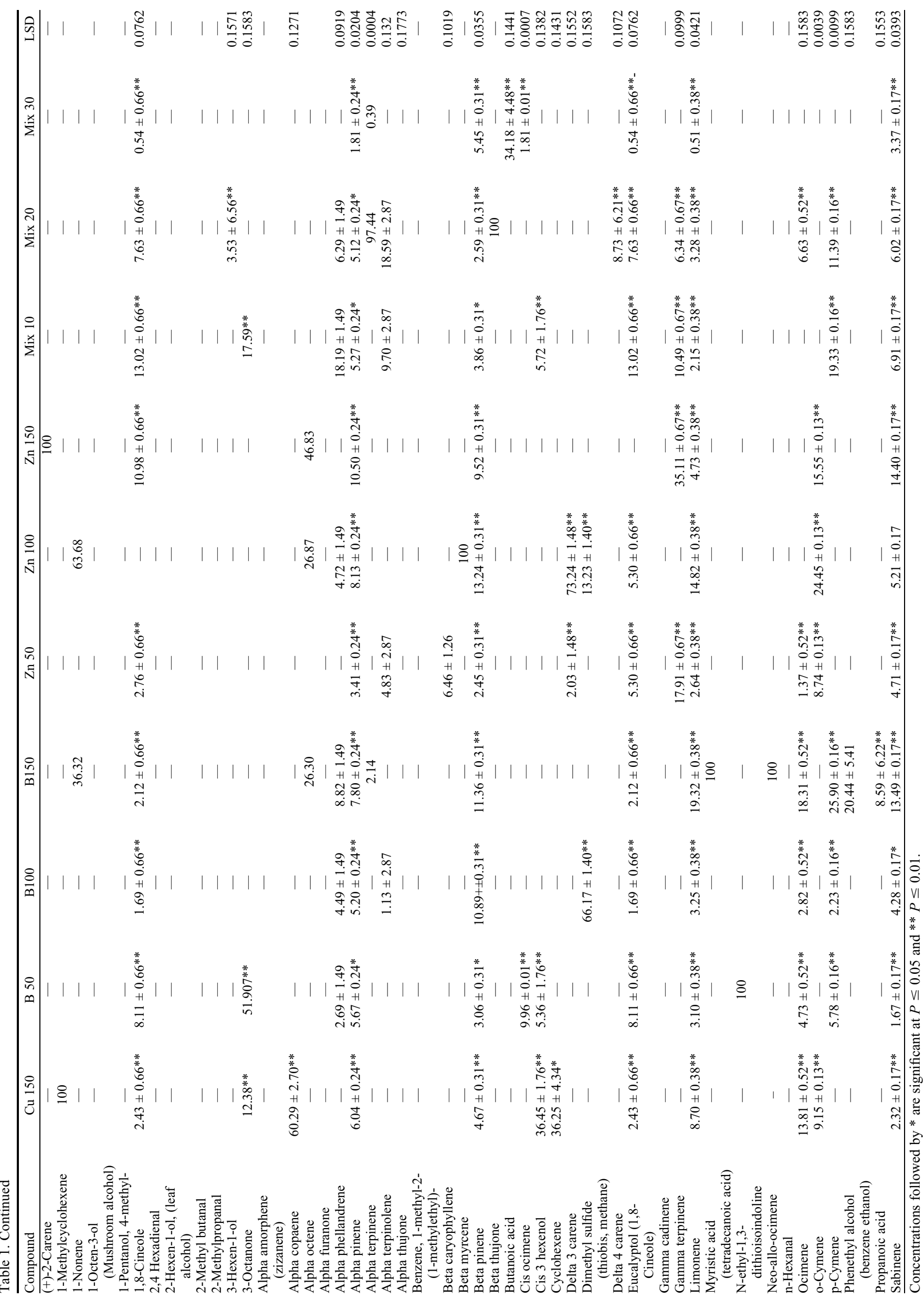


and $97 \mathrm{~mm}$, respectively between winter and summer seasons.

Experimental design. Bush tea was planted in Sept. 2013 according to the method described by Mudau et al. (2007). The plants were then handled by the method described by Maedza et al. (2016). However, instead of four, six foliar separate trials repeated twice for $\mathrm{Zn}, \mathrm{Fe}, \mathrm{Cu}, \mathrm{B}$, and $\mathrm{Mg}$, and a mixture were laid in a randomized complete block design with three levels replicated 10 times. Fertilizer sources included $\mathrm{ZnSO}_{4}, \mathrm{CuSO}_{4}, \mathrm{FeSO}_{4}, \mathrm{Na}_{2} \mathrm{~B}_{8} \mathrm{O}_{13} \cdot 4 \mathrm{H}_{2} \mathrm{O}$, and $\mathrm{MgSO}_{4} \cdot 7 \mathrm{H}_{2} \mathrm{O}$ for $\mathrm{Zn}, \mathrm{Cu}, \mathrm{Fe}, \mathrm{B}$, and $\mathrm{Mg}$, respectively, because of high content of selected micro elements as these are used by farmers and readily available commercially. The macronutrients viz., N, P, and K fertilizers were applied according to the recommended rates described by Mudau et al. (2007) with slight modification by applying them in two splits for two months to avoid stressing the plants. Plant material treatment was according to the method described by Mudau et al. (2007).

Sample preparation. Arboreal plant parts were collected and air-dried in the shade at room temperature. The samples were then pulverized to powder by lyophilizing using liquid nitrogen in a mortar and pestle. Thereafter, they were kept in sealed glass vials and placed in the dark at 2 to $8^{\circ} \mathrm{C}$ until further use (LC-MS). For gas chromatography linked to mass spectrometry (GC-MS), samples consisting of a single leaf per replication per plant were picked $24 \mathrm{~h}$ before being tested from the glasshouse experiment and were kept in airtight Ziplock ${ }^{\circledR}$ bags. These were later transferred using forceps into $\mathrm{GC}-\mathrm{MS}$ headspace screw cap vials.

Gas chromatography linked to mass spectrometry. The samples (one leaf per sample) were analyzed using HS-SPMEGC-MS, a method similar to Musarurwa et al. (2010) but oven ramping temperatures and injection ratios were modified. The HS-SPME of leaves was performed with Supelco ${ }^{\circledR}$ SPME fibers [DVB/Carboxen/ PDMS (Supelco)]. Leaves were placed directly into a $20-\mathrm{mL}$ headspace vial and sealed with an aluminum-coated silicone rubber septum. Volatiles were extracted at $70{ }^{\circ} \mathrm{C}$ for $15 \mathrm{~min}$. The gas chromatography was performed with a Waters GCT Premier AS 2000 instrument coupled to a mass spectrometer, equipped with an HP5 column $(30 \mathrm{~m}$, $0.25 \mathrm{~mm}$ ID, $0.25 \mathrm{~mL}$ film thickness). Temperatures were set at $250{ }^{\circ} \mathrm{C}$ for both the injection (split-less injection) and the ion source temperature. Helium was used as the carrier gas $\left(1 \mathrm{~mL} \cdot \mathrm{min}^{-1}\right)$. The temperature ramp regime was initiated by heating at $50{ }^{\circ} \mathrm{C}$ for $3 \mathrm{~min}$, followed by an oven ramp to $142{ }^{\circ} \mathrm{C}$ at $5{ }^{\circ} \mathrm{C} \cdot \mathrm{min}^{-1}$, and a second ramp of $10^{\circ} \mathrm{C} \cdot \mathrm{min}^{-1}$ up until $240^{\circ} \mathrm{C}$. A mass scanning range of $40-550 \mathrm{~m} / \mathrm{z}$ (perfluoro tri N-butylamine as mass reference) was employed and mass spectra were recorded at $2 \mathrm{scans} / \mathrm{s}$. The NIST library was used in the tentative identification of compounds. Kovat indices were also calculated from an alkane series to verify compound names. Principal component analysis (PCA) and hierarchal clustering analysis were generated using SIMCA 14 statistical software on a matrix of quantities of detected compounds from all treatments. The Proc Capability procedure of SAS (2008) was used to control for normality of the data for the different compound abundances from GC-MS. Thereafter, logarithmic transformation $\left(\log _{10}[x+1]\right)$ was used to normalize the data. To test for significance of micronutrient effects, the general linear model procedure of SAS (2008) was used. Comparisons of means were done using the Tukey post-hoc test.

Liquid chromatography linked to mass spectrometry. The method employed was similar to that used by Nkomo et al. (2014). Extracts were resuspended in $1 \mathrm{~mL}$ of a $50 \%$ $(\mathrm{v} / \mathrm{v})$ mixture of acetonitrile and water $\left(\mathrm{H}_{2} \mathrm{O}\right)$ containing $0.1 \%(\mathrm{v} / \mathrm{v})$ formic acid. The suspensions were vortexed for $1 \mathrm{~min}$ then sonicated for $5 \mathrm{~min}$ and vortexed again for

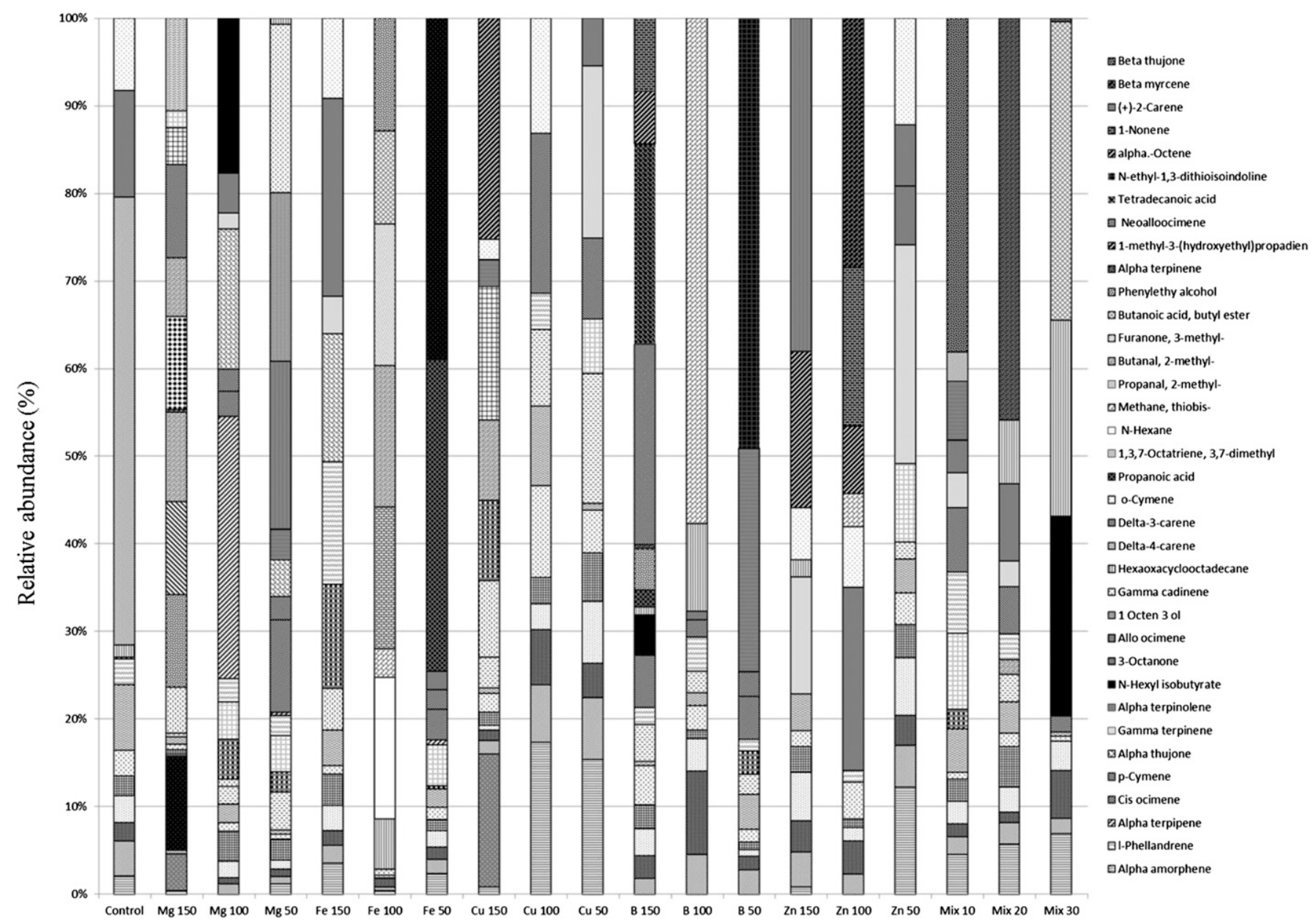

Fig. 1. Relative abundance (\%) of Athrixia phylicoides metabolites in response to different trace element applications. 
$1 \mathrm{~min}$ before spinning at $10,000 \mathrm{rpm}$ for $10 \mathrm{~min}$. Four hundred microliters of the supernatant were pipetted into an LC-MS vial containing a guide. From the vial, the supernatant $(3 \mu \mathrm{L})$ was injected into the LC-MS instrument. Metabolites were separated using a gradient of water $\left(\mathrm{H}_{2} \mathrm{O}\right)$ with $0.1 \%$ formic acid (solvent $\mathrm{A}$ ) and acetonitrile (solvent B), using a Waters UPLC at a flow rate of $0.4 \mathrm{~mL} \cdot \mathrm{min}^{-1}$ on a Waters BEH C18, $2.1 \times$ $50 \mathrm{~mm}$ column. Mass spectrometry was obtained on a Waters SYNAPT G2 MS (Manchester, England) using electron spray ionization running in positive mode with a cone voltage of $15 \mathrm{~V}$. The injections were repeated once to ensure repeatability. Principal component analysis was done using MassLynx software on retention times with molecular weight for all samples.

\section{Results and Discussion}

Phytochemical variation specifically that of volatile compounds detected using $\mathrm{GC}$ MS in all micronutrient application treatments had significant quantitative differences in comparison with the control. In all the treatments, the most prevalent compound groups were terpenes, with some lactones and ketones, the majority having been reported in other plant species mostly in essential oil compositions (Table 1). The table shows the various compounds and relative abundances detected using GC-MS in all the treatments and control of $A$. phylicoides leaves. Significant differences are noted both at $P \leq 0.05$ and $P \leq 0.01$ in each row, whereas a histogram showed the relative abundances of metabolites detected using GC-MS from all treatments (Fig. 1). These data indicate variation of the chemical constituents that are both qualitative and quantitative because of different mineral applications. Control plants had high levels of 1.8 cineole, alpha furanone, alpha terpinolene, delta 3 carene, delta 4 carene, and ocymene at a relative abundance of 13.37; $33.33 ; 13.72 ; 21.73 ; 91.27$; and 14.75 , respectively. None of the other treatments resulted in similar levels of these particular compounds except for alpha furanone that was detected in $\mathrm{Mg} 50$ and $\mathrm{Mg} 100$ at similar relative abundances. Interestingly, the mix 10 treated-plants accumulated relatively more compounds than other nutrient treatments (Table 1; Fig. 1) whereas increasing the concentration of mix to 20 and 30 altered the chemotypic profile significantly, detecting much fewer compounds and in lower levels.

To understand the relatedness of samples, hierarchical clustering was used to reveal six groupings. Group 6 being the largest also had the control embedded together with $\mathrm{Mg} 50,100, \mathrm{Fe} 50,150, \mathrm{Zn} \mathrm{50,}$ $\mathrm{Cu}$ 150, and the Mix 30 (Fig. 2). Clustering did not seem to aggregate on concentration nor micronutrients, thus not explicitly revealing any relatedness according to the treatments. No significant qualitative difference was observed regarding the GC-MS analysis, as can be observed with the six cluster groups all centered close to the control (Fig. 3) with the exception of Fe 100, Mg 150, and $\mathrm{B} 150$. However, there were quantitative differences that were observed between samples and against the control.

A considerable portion of research has been done on the benefits of essential oils to human health. The identified compounds have been documented to possess a plethora of biological properties and have been previously identified in some important South African medicinal plants. For instance, sabinene is a major constituent of carrot seed oil. It also occurs in tea tree oil at low concentrations (Ghafar and Rahman, 2013). There is reason to suggest that coupled with plantenvironment interaction, the application of micronutrients may have indirectly altered the quantities and presence of secondary

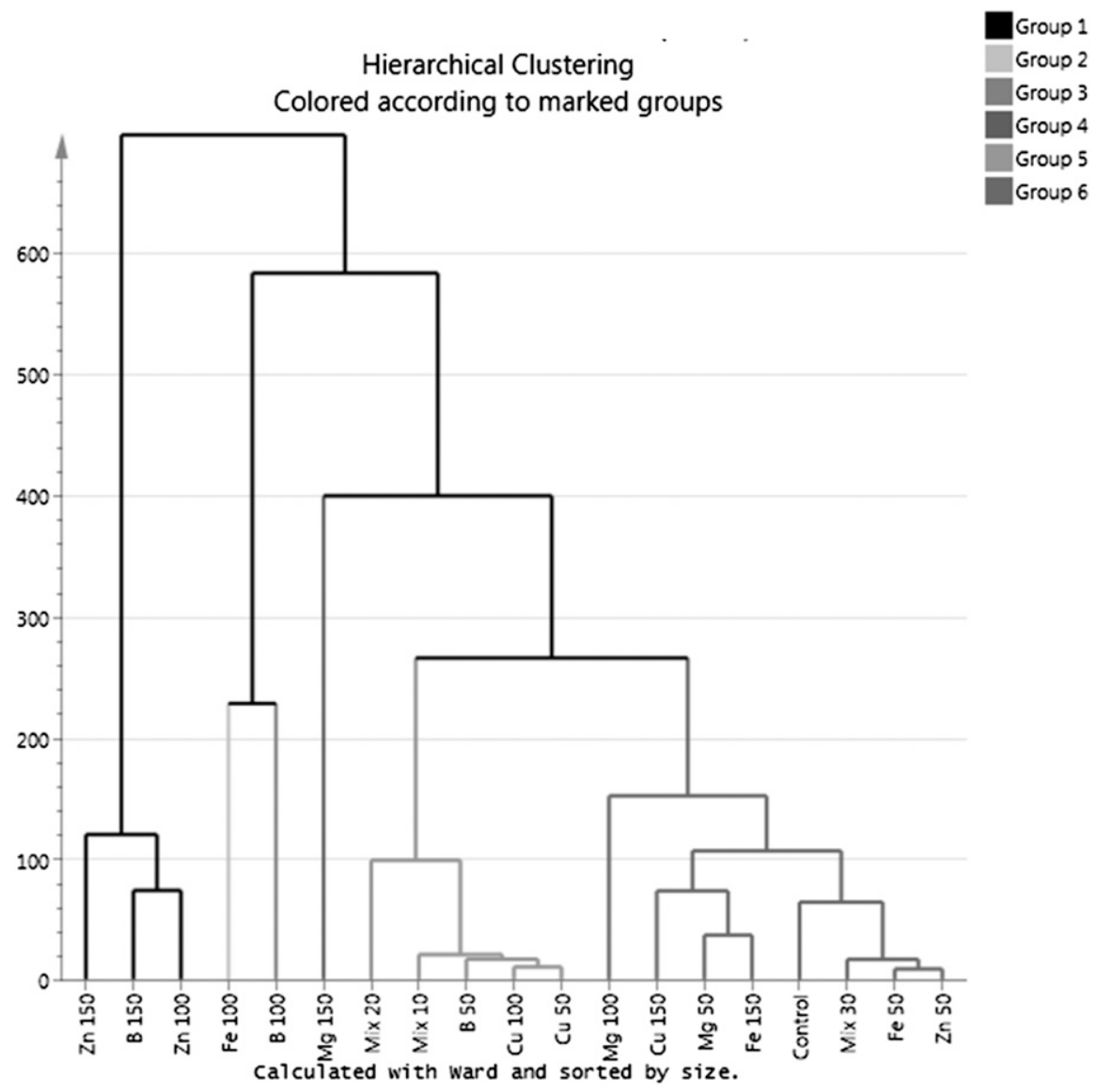

Fig. 2. Hierarchical clustering of on Athrixia phylicoides samples run using gas chromatography linked to mass spectrometry (GC-MS).
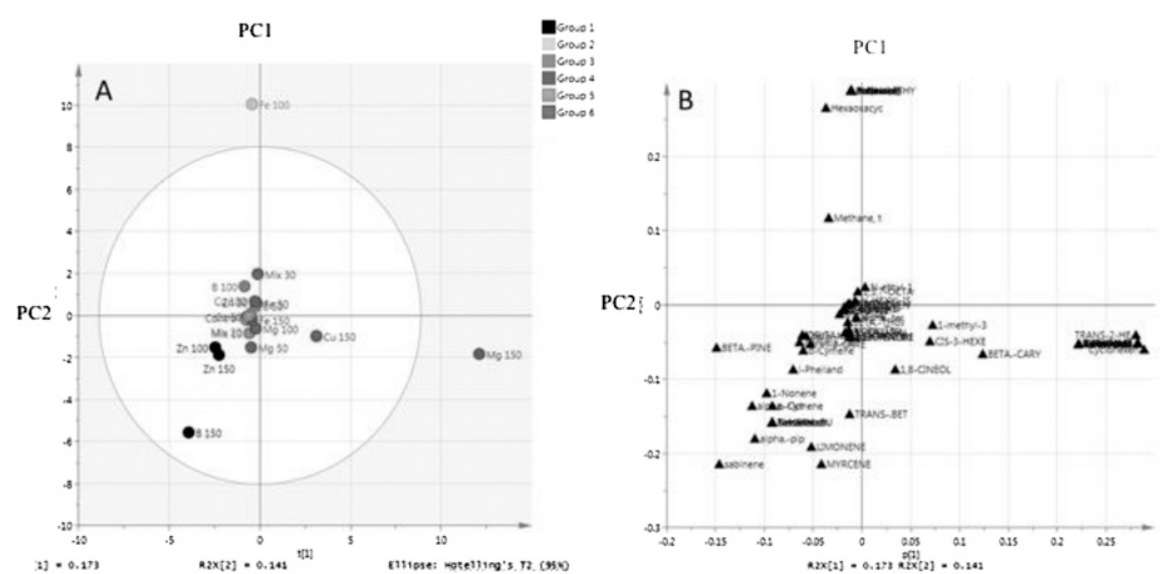

Fig. 3. (A) Score plot and (B) loading plot of the principal component analysis (PCA) on gas chromatography linked to mass spectrometry (GC-MS) data on all micronutrient treatments on Athrixia phylicoides samples. 


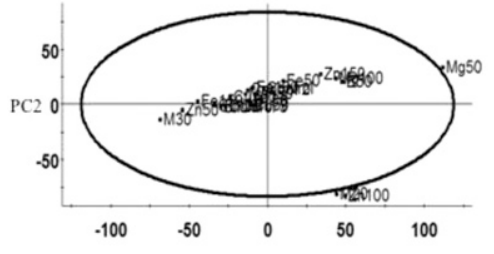

$R 2 X[1]=0.170$ R2X[2] $=0.132$ Hotelling's: T2 (95\%)

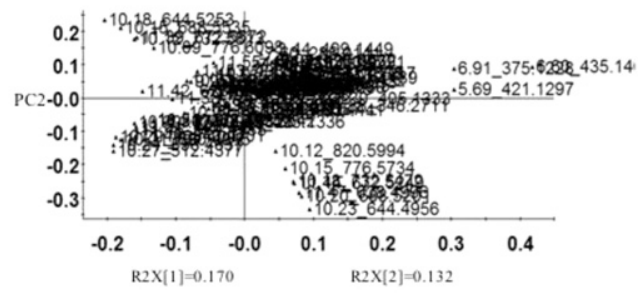

Fig. 4. (A) Score plot and (B) loading plot of the principal component analysis (PCA) on liquid chromatography linked to mass spectrometry (LC-MS) data on all micronutrient treatments on Athrixia phylicoides samples.

metabolites. Micronutrients have been reported to be indirectly impact on secondary metabolite production (Ibrahim and Hawa, 2013) as well as in the formation of coenzymes involved in photosynthetic activities.

In this study, we observed a general increase in compounds detected using GC-MS with an increase in micronutrient application concentration in all treatments (Table 1). This may be due to a 2-fold reason; firstly, an increase in trace element concentrations had a direct influence on photosynthetic activity thus giving rise to more compounds. This is analogous to the effects observed with nitrogen, phosphorus, and potassium application studies on $A$. phylicoides (Mudau et al., 2005; Sitienei et al., 2013). Secondly, particularly with boron, an increase in the application concentration triggered a response in which the plants had been stressed, thus indirectly influencing the production of secondary metabolites. This phenomenon in tea has been reported by Omwoyo et al. (2013) in which volatile flavor compound composition in Camellia sinensis was greatly affected by growing environment; albeit, reported to be partially influenced by genotypic variation and clonal selection in black tea breeding programs. However, in this study this may not be a consideration as the plant material was collected in the same area and treated differently during the experiment.

There were, however, no significant qualitative differences indicated by the clustering of hierarchical groups together (Fig. 3A), suggesting supplementary application of micronutrients to $A$. phylicoides may not directly influence production of more secondary metabolites, contrary to some studies (Sitienei et al., 2013). The discriminating compounds for $\mathrm{Fe} 100$ were benzene ethanol, ocimene, and hexaoxycyclooctadecane; these are mostly used for perfumery. Compounds that discriminated Mg 150, included cyclohexene, trans 2 hexenal, and two other compounds (Fig. 3B). However, the discriminating compounds from the three samples that were furthest from the control seem not to have a direct influence on PAR and photosynthetic activities nor in the metabolism and storage of micronutrients; hence, in this study they are of no significant interest. The groupings seen in the clustering
(Fig. 2) are possibly because of the quantitative differences, which is similar to the phenomenon explained by Omwoyo et al. (2013).

Assessing chemotypic variation using LC-MS did not reveal significant qualitative differences as was the case with GC-MS in all the samples as seen by the grouping of samples in the middle (Fig. 3A). However, samples Mix 20, Zn 100, and Mg 50 showed a marked difference with all the other samples, with $\mathrm{Mg} 50$ being significantly different from the rest because of peaks at 5.69 and 6.91 retention times with 421.1 and $375.6 \mathrm{~m} / \mathrm{z}$ molecular weights. For Mix 20 and Zn 100, discriminating peaks were 10.12, 10.15, $10.18,10.20$, and 10.23 min retention times with molecular weights ranging from 644.49 (smallest) to 776.57 and $820.59 \mathrm{~m} / z$ (Fig. 4B). Elemental compositions of these compounds at the latter retention times show a great similarity with sesquiterpenes. Results did reveal quantitative differences, which is still congruent with the findings from GC-MS. Thus, we may tentatively suggest that in increasing the concentration of trace element application, there is a perceived increase in compounds.

The increase in phytochemicals because of increased trace element application can also thus be indirectly linked to an increase in primary metabolite production with a simultaneous increase in the concentration of trace elements in A. phylicoides. These differences may not only cause organoleptic changes but also alter the health-related benefits of the tea because of a different suite of chemicals accumulating in plants grown under various mineral elements.

In conclusion, all application treatments had significant quantitative differences in comparison with the control in compounds detected using GC-MS. Although LC-MS profiling showed no significant qualitative differences within the treatments and between the treatments to the control, there were quantitative differences between the control and all other treatments. Foliar application of the studied micronutrients did have an influence on the metabolite quantities as has been reported with most secondary metabolite fluctuations caused by plant-environment interactions. the production and concentration of desirable

\section{Literature Cited}

Bryant, J.P., F.S. Chapin, III, and D.R. Klein. 1983. Carbon/nutrient balance of boreal plants in relation to vertebrate herbivory. Oikos 40: 357-368.

Bryant, J.P., F.S. Chapin, III, P. Reichardt, and T. Clausen. 1987. Responses of winter chemical defense in Alaska paper birch and green alder to manipulation of plant carbon: Nutrient balance. Oecologia 7:510-514.

Coley, P.D., J.P. Bryant, and F.S. Chapin, III. 1985. Resource availability and plant antiherbivore defense. Science 23:895-899.

Ghafar, A. and A. Rahman. 2013. Optimisation of kaffir lime leaves (Citrus hystrix) volatile oil extraction by pressurised liquid extraction (PLE) using response surface methodology (RSM). Universiti Teknologi MARA, PhD Diss.

Haukioja, E., V. Ossipov, J. Koricheva, T. Honkanen, S. Larsson, and K. Lempa. 1998. Biosynthetic origin of carbon-based secondary compounds: Cause of variable responses of woody plants to fertilization. Chemoecology 8:133-139.

Ibrahim, A.K., A. Usman, B. Abubakar, and U.H. Aminu. 2011. Extractable micronutrients status in relation to other soil properties in Billiri Local Government Area. J. Soil Sci. Environ. Mgt. 3:282-285.

Ibrahim, M.H. and H.Z.E. Jaafar. 2013. Abscisic acid induced changes in production of primary and secondary metabolites, photosynthetic capacity, antioxidant capability, antioxidant enzymes and lipoxygenase inhibitory activity of Orthosiphon stamineus Benth. Molecules 18:7957-7976.

Joubert, E., W.C.A. Gelderblom, A. Louw, and D. de Beer. 2008. South African herbal teas: Aspalathus linearis, Cyclopia spp. and Athrixia phylicoides - A review. J. Ethnopharmacol. 119:376-412.

Mabogo, D.N.E. 1990. The ethnobotany of Vhavenda. Univ. Pretoria. Pretoria, MSc Diss.

Maedza, K.V., M. Nkomo, W. Ngezimana, and F.N. Mudau. 2016. Effects of foliar spray application of selected micronutrients on the quality of bush tea. HortScience 51:873879 .

Maudu, M.E., F.N. Mudau, and I.K. Mariga. 2013. The effect of gibberellins on sprouting of cuttings and quality of bush tea (Athrixia phylicoides DC). Afr. J. Biotechnol. 10:87418745.

Mbambezeli, G. 2005. Athrixia phylicoides. South African National Biodiversity Institute, Pretoria.

Mudau, F.N. 2007. Growth, development and chemical composition of bush tea (Athrixia phylicoides L.) as affected by seasonal nitrogen, phosphorus and potassium nutrition. University of Pretoria, South Africa, PhD Diss. for Plant Production and Soil Science.

Mudau, F.N., H.T. Araya, E.S. Du Toit, P. Soundy, and J. Olivier. 2007. Bush tea (Athrixia phylicoides L.) as an alternative herbal and medicinal plant in Southern Africa: Opportunity for commercialization. Med. Aromat. Plant Sci. Biotechnol. 1:70-73.

Mudau, F.N., P. Soundy, and E.S. Du Toit. 2005. Plant growth and development of bush tea as affected by nitrogen, phosphorus, and potassium nutrition. HortScience 40: 1898-1901.

Musarurwa, H.T., J. van Staden, and N.P. Makunga. 2010. In vitro seed germination and cultivation of the aromatic medicinal Salvia 
stenophylla (Burch. ex Benth.) provides an alternative source of $\alpha$-bisabolol. Plant Growth Regulat. 61:287-295.

Nkomo, M., D.K. Katerere, H. Vismer, T. Cruz, S. Balayssac, M.M. Malet-Martino, and N.P. Makunga. 2014. Fusarium inhibition by wild populations of the medicinal plant Salvia africanalutea $\mathrm{L}$. linked to metabolomic profiling. BMC Complement. Altern. Med. 14:99.

Omwoyo, W.N., P.O. Owuor, D.M. Ongeri, and D.M. Kamau. 2013. Effect of genotypes in different tea-growing locations in Kenya on some micronutrients content of black tea. Intl. J. Tea Sci. 9:6-13.

Omwoyo, W.N., P.O. Owuor, D.M. Ongeri, and D.M. Kamau. 2014. Effect of genotypes in different environments on micronutrient content of black tea. J. Tea Sci. Res. 4:17-26.

Owuor, P.O., C.O. Othieno, J.M. Robinson, and K. Baker. 1991. Response of tea quality parameters to time of year and nitrogen fertilizer. J. Sci. Food Agr. 55:1-11.

Owuor, P.O., K.W. Ng'etich, and M. Obanda. 2000. Quality response of clonal black tea to nitrogen fertilizer, plucking interval and plucking standard. J. Sci. Food Agr. 70: 47-52.

Roberts, M. 1990. Indigenous healing plants. 1st ed. Southern Book Publishers, Halfway House. p. $56-57$.

SAS. 2008. SAS/STAT ${ }^{\circledR}$ software release 9.2. SAS Institute Inc., Cary, NC.
Sedaghathoor, S., A.M. Torkashvand, D. Hashemabadi, and B. Kaviani. 2009. Yield and quality response of tea plant to fertilizers. Afr. J. Agr. Res. 4:568-570.

Sitienei, K., P.G. Home, D.M. Kamau, and J.K. Wanyoko. 2013. The influence of fertilizer type and application rates in tea cultivation on nitrogen and potassium efficiencies. Afr. J. Agr. Res. 8:3770-3777.

Street, R., J. Száková, O. Drábek, and I. Mládková. 2006. The status of micronutrients $(\mathrm{Cu}, \mathrm{Fe}, \mathrm{Mn}$, $\mathrm{Zn})$ in tea and tea infusions in selected samples imported to the Czech Republic. Czech J. Food Sci. 24:62-71.

Wanyoko, J.K. 1983. Fertilizer on tea: Nitrogena review. Tea 4:28-35. 